\title{
A rapid and accurate solar tracker (notice of removal)
}

\section{Baoping Xiao, Lijun Xu}

Baoping Xiao, Lijun Xu, "A rapid and accurate solar tracker (notice of removal)," Proc. SPIE 7130, Fourth International Symposium on Precision Mechanical Measurements, 713043 (31 December 2008); doi: 10.1117/12.819706

SPIE Event: Fourth International Symposium on Precision Mechanical Measurements, 2008, Anhui, China 


\title{
A rapid and accurate solar tracker (notice of removal)
}

\author{
Proc. SPIE 7130, 713043 (2008); http://dx.doi.org/10.1117/12.819706
}

Online Publication Date: 31 December 2008

Retracted from Publication: 12 April 2010

Conference Date: 29 August 2008

Conference Location: Hefei/J iuhua Mountain, Anhui, China

Conference Title: Fourth International Symposium on Precision Mechanical Measurements

Conference Chairs: Yetai Fei, Kuang-Chao Fan, Rongsheng Lu

Baoping Xiao

Zhejiang Univ. (China) and China Jiliang Univ. (China)

Lijun Xu

China Jiliang Univ. (China)

This paper (713043) was removed from the SPIE Digital Library on 13 April 2010 due to discovery of plagiarism. As stated in the SPIE Guidelines for Professional Conduct and Publishing Ethics, SPIE defines plagiarism as the reuse of someone else's prior ideas, processes, results, or words without explicit attribution of the original author and source, or falsely representing someone else's work as one's own. SPIE considers plagiarism in any form, at any level, to be unacceptable and a serious breach of professional conduct. It is SPIE policy to remove such papers and to take appropriate corrective or disciplinary action against the offending author(s). 